\title{
MORFOLOGIA E DESENVOLVIMENTO DE SCHISTOSOMA MANSONI SAMBON, 1907 EM INFECÇOEES UNISSEXUAIS EXPERIMENTALMENTE PRODUZIDAS NO CAMUNDONGO *
}

\author{
Eliana Maria Zanotti ** \\ Luiz Augusto Magalhães ** \\ Aquiles Eugenico Piedrabuena**
}

\begin{abstract}
ZANOTTI, E. M. et al. Morfologia e desenvolvimento de Schistosoma mansoni Sambon, 1907 em infecçóes unissexuais experimentalmente produzidas no camundongo. Rev. Saúde pưbl,, S. Paulo, 16:114-9, 1982.

RESUMO: Estudou-se o desenvolvimento de Schistosoma mansoni em infecções unissexuais no camundongo. Os esquistossomos fêmeos apresentaram-se menos desenvolvidos do que os machos. Houve correlação entre o comprimento dos machos e o número de testículos. Verificou-se que 0 isolamento sexual é prejudicial aos dois sexos, principalmente à fêmea.
\end{abstract}

UNITERMOS: Schistosoma mansoni. Esquistossomose mansônica.

\section{INTRODUÇÃO}

Com relação ao desenvolvimento de Schistosoma mansoni Sambon ${ }^{8}, 1907$ no hospedeiro definitivo, Sagawa e col. ${ }^{7}$ (1928) estabeleceram que o acasalamento concorre para o desenvolvimento de esquistossomos dos dois sexos, mas que a associação macho-fêmea concorre mais ainda para a maturação da fêmea.

Observações de Maldonado e Herrera ${ }^{3}$ (1949), Paraense e Santos 5 (1949) e Paraense ${ }^{4}$ (1949) sobre o precário desenvolvimento das estruturas somáticas e germinativas das fêmeas de $S$. mansoni, em infecções unissexuais, confirmaram os dados obtidos por Sagawa e col. ${ }^{7}$ e Severinghaus ${ }^{9}$ (1928) para Schistosoma japonicum.

Sobre o desenvolvimento de $S$. mansoni, Shaw ${ }^{10}$ (1977) assinalou, após estudos "in vitro", que as fêmeas só se desenvolvem plenamente após contato íntimo com o canal ginecófaro dos machos, sugerindo de acordo com Severinghaus ${ }^{9}$ e Sagawa e col.7, uma estimulação hormonal por parte dos machos.

Casos de hermafroditismo secundário do macho, em infecçōes unissexuais, foram descritos por Vogel 13 (1947), Short ${ }^{11}$ (1948), Paraense 4 (1949) e Ruiz e Coelho ${ }^{\circ}$ (1952).

Em infeç̧ões unissexuais por machos, estes se apresentaram plenamente desenvolvidos, observando-se, em alguns casos, testículos supranumerários (Paraense 4. 1049).

No presente experimento tratou-se de estudar aspectos da morfologia e do desen-

\footnotetext{
* Pesquisa financiada pelo CNPq/FAPESP . Processos n's 2.222-8-077/78 e 04-77/079, respectivamente.

* Do Instituto de Biologia da Universidade Estadual de Campinas. . Caixa Postal 6.109. Barão Geraldo - 13100 - Campinas, SP - Brasil.
} 
ZANOTTI, E.M. et al. Morfologia e desenvolvimento de Schistosoma mansoni Sambon, 1907 em infeções unissexuais experimentalmente prodtzidas no camundongo. Rev. Saúde públ., S. Paulo, 16:114-9, 1982.

volvimento de $S$. mansoni em camundongos submetidos a infecção unissexual.

\section{MATERIAL E METODOS}

Foram infectados com miracídios de $S$. mansoni da linhagem $\mathrm{BH}$ exemplares de Biomphalaria glabrata descendentes de uma população de Belo Horizonte, $M G$, criados em laboratório.

Para a obtenção de infecções unissexuais, cada exemplar de molusco foi exposto a um único miracidio e para as infecções bissexuais cada caramujo foi exposto a 10 miracidios.

Camundongos albinos foram infectados pela exposição da cauda a uma suspensão aquosa contendo 100 cercárias (Magalhães 1, 1969).

Foram constituidos très grupos de roedores: infectados unicamente por esquistossomos fêmeos, infectados unicamente por esquistossomos machos e infectados por machos e fêmeas.

Sessenta dias após a infecção os camundongos foram sacrificados e recolhidos os esquistossomos por perfusão do plexo porta e fígado (Yolles e col.14, 1947).

Os trematódeos foram fixados em Raillet-Henry ou em álcool a 70\% e corados com carmim cloridrico ou hematoxilina de Erlich.

Foram contados testitulos, verificada a presença de ovos e anotado o comprimento dos vermes. Observaram-se aspectos gerais da morfologia dos vermes.

Os parâmetros correspondentes as infecções bissexuais e unissexuais foram tratados pelo teste " $t$ " de Student, tomando-se como nivel de rejeição $\mathrm{H}_{\circ}$ (hipótese nula) $5 \%$, assinalando-se, entretanto, sempre os niveis máximos. Determinou-se a correlação existente e seu grau de significância entre os comprimentos dos vermes machos e o número de testículos, utilizando-se o teste " $B$ " (Brieger).

\section{RESULTADOS}

Nas Tabelas 1 e 2 apresentamos o comprimento médio dos machos e o número de testítulos e a percentagem de ovos observados em esquistossomos colhidos em camundongos com infecções bi e unissexuais.

Estatisticamente, verificamos que os vermes machos da infecção bissexual apresentaram comprimento maior quando comparados com vermes machos obtidos em infecção unissexual $(\mathrm{t}=3,417$, significativo a nível de $1 \%$ ).

O comprimento dos esquistossomos fêmeos obtidos em camundongos com infecção bissexual foi muito maior que o comprimento dos esquistossomos fêmeos obtidos em infecção unissexual $(\mathrm{t}=12,05$, significativo a nível de $0,1 \%$ ).

Através das Tabelas 1 e 2 verificamos que os vermes machos apresentaram comprimento maior que as fêmeas independentemente do tipo de infecção.

Com relação aos lóbulos testiculares, verificamos que os vermes colhidos em camundongos com infecção bissexual apresentaram maior número de glândulas do que as observadas nos vermes obtidos de infecção unissexual ( $\mathrm{t}=2,377$, significativo a nivel de $5 \%$ ).

O comprimento dos vermes machos mostrou estreita relação com o número de testículos, de maneira que vermes maiores apresentaram número maior de testículos. Esta correlaçăo foi válida para vermes colhidos em camundongos com infecções bi e unissexual $(\mathrm{r}=0,8151$, significativo a nivel de $0,1 \%$, para infecção bissexual $\mathrm{e}$ $r=0,6618$, significativo a nivel de $0,1 \%$, para infecção unissexual).

Em duas ocasiōes, em camundongos portadores de infecções unissexual, observamos vermes que continham respectivamente, $26 \mathrm{e}$ 
ZANOTTI, E.M. et al. Morfologia e desenvolvimento de Schistosoma mansoni Sambon, 1907 em infeç̧óes unissexuais experimentalmente prodızidas no camundongo, Rev. Saúde públ., $\mathrm{S}$. Paulo, 16:114-9, 1982.

\section{T A B E L A 1}

Dados obtidos de esquistossomos colhidos em 51 camundongos portadores de infecção unissexual por machos e em 30 camundongos portadores de infecção unissexual por fêmeas.

\begin{tabular}{|c|c|c|c|c|}
\hline \multicolumn{5}{|c|}{ Infecção Unissexual } \\
\hline & \multicolumn{2}{|c|}{$\begin{array}{c}\text { Esquistossomos } \\
\text { machos }\end{array}$} & \multicolumn{2}{|c|}{$\begin{array}{l}\text { Esquistossomos } \\
\text { fêmeos }\end{array}$} \\
\hline & $\begin{array}{l}\text { Comprimento } \\
\text { do verme } \\
(\mathrm{mm})\end{array}$ & $\begin{array}{l}\text { Número de } \\
\text { testículos }\end{array}$ & $\begin{array}{l}\text { Comprimento } \\
\text { do verme } \\
(\mathrm{mm})\end{array}$ & $\begin{array}{c}\text { Femeas com } \\
\text { um ovo } \\
\%\end{array}$ \\
\hline Média & $5,82 \pm 1,14$ & $7,80 \pm 0.54$ & $3,48 \pm 0,21$ & 0 \\
\hline $\begin{array}{l}\text { Coeficiente } \\
\text { de variação }\end{array}$ & 19,6 & 6,9 & 6,1 & 0 \\
\hline
\end{tabular}

T A B E L A 2

Dados obtidos de esquistossomos colhidos em 15 camundongos com infecção bissexual.

Infecção Bissexual

\begin{tabular}{|c|c|c|c|c|}
\hline & \multicolumn{2}{|c|}{$\begin{array}{c}\text { Esquistossomos } \\
\text { machos }\end{array}$} & \multicolumn{2}{|c|}{$\begin{array}{c}\text { Esquistossomos } \\
\text { fêmeos }\end{array}$} \\
\hline & $\begin{array}{l}\text { Comprimento } \\
\text { do verme } \\
(\mathrm{mm})\end{array}$ & $\begin{array}{l}\text { Número de } \\
\text { testíc: }: \text { los }\end{array}$ & $\begin{array}{l}\text { Comprimento } \\
\text { do verme } \\
(\mathrm{mm})\end{array}$ & $\begin{array}{c}\text { Femeas com } \\
\text { um ovo } \\
\%\end{array}$ \\
\hline Média & $6,68 \pm 0,75$ & $8,13 \pm 0,45$ & $5,61 \pm 0,67$ & $74,46 \pm 12,33$ \\
\hline $\begin{array}{l}\text { Coeficiente } \\
\text { de variação }\end{array}$ & 10,5 & 5,5 & 11,9 & 16,6 \\
\hline
\end{tabular}

35 lóbulos testiculares (Fig. 1). Alguns esquistossomos machos, geralmente de tamanho reduzido, não apresentaram testiculns (Fig. 2). Estes vermes eram observados com freqüência no interior do canal ginecófaro de outros machos (Fig. 3). Vermes machos de tamanho reduzido apresentaram às vezes aspecto atarracado como mostra a Fig. 4.

Os ovos de $S$. mansoni não furam vistos no útero de fêmeas obtidas em infecção unissexual. O sistema reprodutor mostrou-se pouco desenvolvido (Fig. 5).

Os esquistossomos fêmeos colhidos de roedores com infecção bissexual freqüentemente apresentaram-se com um ovo no útero (Tabela 2).

Não foram verificados casos de hermafroditismo.

Alguns machos apresentaram formaçōes lobulares no terço médio de seu corpo; 
ZANOTTI, E.M. et al. Morfologia e desenvolvimento de Schistosoma mansoni Sambon, $1907 \mathrm{em}$ infecços unissexuais experimentalmente prodizidas no camunđongo. Rev. Saúde públ., $\mathbf{S}$. Paulo, 16:114-9, 1982.

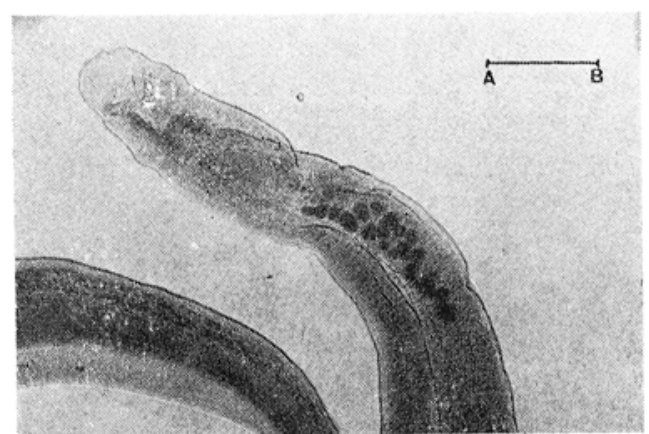

Fig. 1 - Esquistossomo maoho contendo 26 lóbulos testiculares, obtido em infeç̧ão unissexual $\overline{(A B}==0,33 \mathrm{~mm})$.

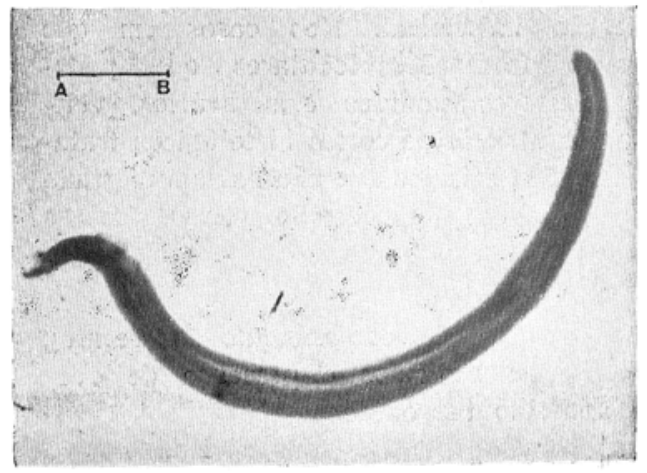

Fig. 2 - Esquistossomo macho, pouco desenvolvido, obtido em infecção unissexual $\overline{(\mathrm{AB}}==0,43 \mathrm{~mm})$.

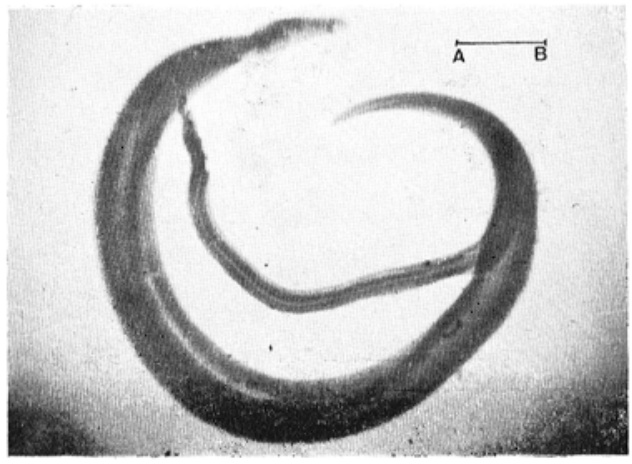

Fig. 3 - Esquistossomo macho, pouco desenvolvido, obtido em infecção unissexual. encontrado no canal ginecófaro de outro esquistossomo macho $\overline{(\mathrm{AB}}$ $=0.55 \mathrm{~mm}$ ).

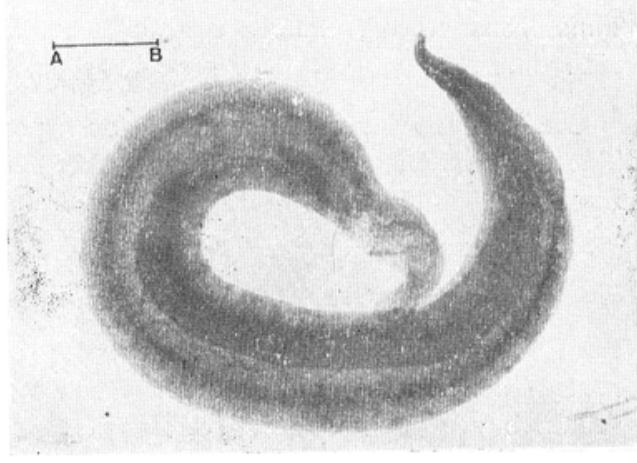

Fig. 4-Esquistossomo macho, de aspecto atarracado, observado em infeç̧óes unissexuais $(\overline{\mathrm{AB}}==0,50 \mathrm{~mm})$.

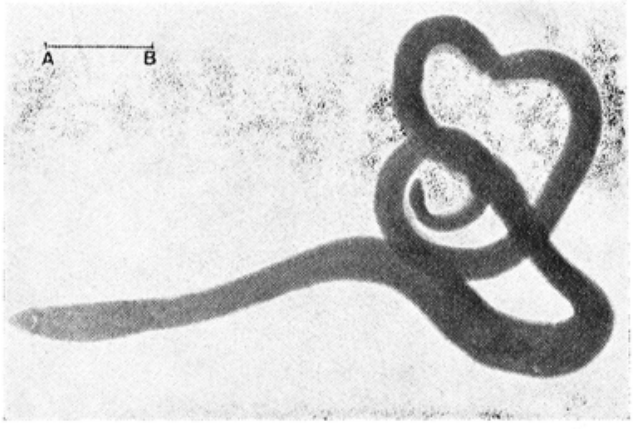

Fig. 5 - Esquistossomo femeo, pouco desenvolvido, obtido em infecção unissexual $\overline{(A B}==0,22 \mathrm{~mm})$.

através de cortes histológicos verificamos tratarem-se de lóbulos testiculares, tendo sido observadas espermátides no canal deferente destes lóbulos.

Não constatamos relação entre o sexo do hospedeiro e o comprimento dos vermes, número de testículos e a presença de ovos no aparelho reprodutor, tanto nas infecções bi como unissexuais.

\section{DISCUSSÃO E CONCLUSÖES}

Em 1919, Tanabe 12 sugeriu que o sexo nos esquistossomatídeos é determinado por ocasião da fertilização do ovo e que muitos 
ZANOTTI, E.M. et al. Morfologia e desenvolvimento de Schistosoma mansoni Sambon, 1907 em infecçסes unissexuais experimentalmente prodizidas no camundongo. Rev. Saúde públ., $\mathrm{s}$. Paulo, 16:114-9, 1982.

estágios do ciclo biológico não apresentam dimorfismo sexual, embora o sexo já tenha sido determinado.

Confirmando resultados obtidos por Tanabe 12 (1919), Severinghaus ${ }^{9}$ (1928) e Sagawa e col. ${ }^{7}$ (1928) para S. japonicum, verificamos que de animais infectados com cercárias provenientes de moluscos expostos a um único miracídio, obtém-se vermes de um só sexo. Os vermes geralmente apresentam deficiências em seu desenvolvimento somático e germinativo, conforme demonstrado por Severinghaus ${ }^{9}$ (1928), Maldonado e Herrera $^{3}$ (1949), Paraense e Santos 5 (1949) e Paraense ${ }^{4}$ (1949).

Verificamos também, concordando com Sagawa e col.7 (1928), que a ausência da associação macho-fêmea é mais lesiva ao desenvolvimento do esquistossomo fêmeo. Este fato pode ser constatado analisando-se os dados constantes das Tabelas 1 e 2 .

Em 1973, Magalhães e Carvalho 2 estudando as linhagens $\mathrm{BH}$ e SJ de $S$. mansoni verificaram que em infecção bissexual, os esquistossomos $\mathrm{BH}$ eram mais longos que os de SJ e os machos BH apresentavam maior número de testículos. No presente trabalho assinala-se também uma correlação entre o comprimento dos vermes e o número de testículos.
Contrariando o que se descreve tradicionalmente, os vermes machos por nós colhidos em infecção bissexual eram mais longos que as fêmeas.

Foi notável a influência do acasalamento no desenvolvimento do aparelho reprodutor, principalmente dos vermes fêmeos. Excepcionalmente em infecçōes unissexuais encontramos dois vermes com grande número de lobos testiculares. Observamos numerosos casos de homossexualismo entre machos em infecção unissexual.

Não confirmamos observações de Vogel 13 (1947), Short 11 (1948), Paraense 4 (1949) e Ruiz e Coelho ${ }^{6}$ (1952) que descreveram hermafroditismo secundário de machos em infecção unissexual. Nos casos em que haviam formações lobulares que poderiam ser confundidas com ovários, verificamos através de cortes histológicos tratarem-se de testículos que não haviam migrado para o terço anterior do verme. Nesses cortes foi possivel observar espermátides.

Não encontramos correlação entre o sexo do hospedeiro e o comprimento dos vermes, número de testículos e presença de ovos no aparelho reprodutor.

Concluímos que nas infecções unissexuais tanto esquistossomos machos como fêmeos apresentaram evidente deficiência de desenvolvimento.

ZANOTTI, E. M. et al. [Morphology and development of Schistosoma mansoni Sambon, 1907 in unisexual infections produced experimentally in mice]. Rev. Saúde pábl., S. Paulo, 16:114-9, 1982.

ABSTRACT: The Schistosoma mansoni development in mice submitted to unisexual infections was studied. The single female worms developed less than the single males. There was correlation between the male's length and the number of his tests. It was verified that sexual isolation of the schistosomes is prejudicial to both sexes, mainly for the female.

UNITERMS: Schistosoma mansoni. Schistosomiasis. 
ZANOTTI, E.M. et al. Morfologia e desenvolvimento de Schistosoma mansoni Sambon, 1907 em infecçōes unissexuais experimentalmente produzidas no camundongo. Rev. Saúde públ., $\mathbf{S}$. Paulo, 16:114-9, 1982.

\section{REFERENCIAS BIBLIOGRAFICAS}

1. MAGALHAES, L,A. Técnica para avaliação da viabilidade de penetração de cercárias de Schistosoma mansoni em Mus musculus, Hospital, Rio de Janeiro, 75:16636, 1969.

2. MAGALHAES, L.A. \& CARVALHO, J.F. Estudo morfológico de Schistosoma mansoni pertencentes a linhagens de Belo Horizonte (MG) e do Vale do Rio Paraíba (SP). Rev. Saúde puibl., S. Paulo, 7:289$-94,1973$.

3. MALDONADO, J.F. \& HERRERA, F.V. Schistosoma mansoni infection resulting from exposure to cercariae proceeding from a single naturally infected snail. Puerto Rico J. publ. Hith, 25:231-41, 1949.

4. PARAENSE, W.I. Observaçōes adicionais sobre o sexo do Schistosoma mansont nas infecções por cercárias de um ünico molusco. Mem. Inst. Oswaldo Cruz, 47:535-46, 1949.

5. PARAENSE, W.L. \& SANTOS, J.M. o sexo do Schistosoma mansoni nas infecções produzidas por cercárias de um único molusco. Mem. Inst. Oswaldo Cruz, $47: 35-49,1949$.

6. RUIZ, J.M. \& COELHO, E. Schistosomose experimental. 2. Hermafroditismo do Schistosoma mansoni verificado $\mathrm{em}$ cobaia. Mem. Inst. Butantan, 24:115-26, 1952.

7. SAGAWA, E.; OGI, K. \& SUMIKOSHI, Y. Study concerning the influence of sex on the growth of animal bodies. 1st. report: experiment on Schistosoma japonicum. Trans. Jap. Path. Soc., 16:494-500, 1928.
8. SAMBON, L.W. Descriptions of some new species of animal parasites. Proc. zool. Soc. London, p. 282-3, 1907. [separata]

9. SEVERINGHAUS, A.E. Sex studies on Schistosoma japonicum. Quart. J. microsc. Sci., 71:653-702, 1928.

10. SHAW, J.R. Schistosoma mansoni: pairing in vitro and development of females from single sex infections. Exp. Parasit., 41:54-65, 1977 .

11. SHORT, R.B. Hermaphrodites in a Puerto Rican strain of Schistosoma mansoni. $J$. parasit., $34: 240-2,1948$.

12. TANABE, $\mathrm{K}$. A contribution of the knowledge of the morfology and development of Schistosoma japonicum. Igaku Chuo-Zashi, 17(6), 1919. Apud STANDEN, O.D. The relationship of sex in Schistosoma mansoni to migration within the hepatic portal system of experimentally infected mice. Ann. trop. Med. Parasit., 67:425-30, 1953.

13. VOGEL, H. Hermaphrodites of Schistosoma mansoni. Ann. trop. Med. Parasit., 41 :266-77, 1947.

14. YOLLES, T.K.; MOORE, P.V.; DE GINSTI, D.L.; RIPSON, C.A. \& MELENEY, H.E. A technique for the perfusion of laboratory animals for the recovery of schistosomes. J. Parasit., 33:419-26, 1947.

Recebido para publicação em 02/10/1981

Aprovado para publicasão em 17/02/1982 